\title{
Optical coherence tomography holds promise for conserving art
}

Piotr Targowski, Michalina Góra, Jan Marczak, Antoni Rycyk, and Bogumila J. Rouba

Optical coherence tomography (OCT) has migrated successfully from medical imaging to materials science, where it is used online to monitor varnish removal from paintings.

Noninvasive examinations of human patients and art objects share more than the important modus operandi of 'do no harm.' Soon after medical x-rays were discovered, they were applied to inspect the underlying layers of paintings. More recently, that extended to the newer modality of x-ray tomography. Now, optical coherence tomography (OCT), which acquires and processes optical signals to produce high-quality 3D images, has entered the picture. Medical OCT was first described in $1991,{ }^{1}$ and reports of its use to examine artwork ${ }^{2-4}$ emerged in 2004.

OCT uses low-coherence interferometry, a tool to study lightwave properties, to determine the distance to the scattering center in an object that moderately absorbs light. The light source's spectral width determines the localization precision: IR broadband light sources spanning 200nm allow for better than $2 \mu \mathrm{m}$ axial resolution. While this is still less than in phase interferometry, the result is free of the phase-ambiguity disadvantages that limit the height difference between two adjacent data points. The most popular interferometer configuration is Michelson's type (see Figure 1), in which scattering-center positions are recovered from interference-fringe frequencies superimposed on the light sources' spectra.

In our conservation experiment, we used a home-grown instrument ${ }^{5}$ with $4 \mu \mathrm{m}$ axial resolution at a central wavelength of $\lambda=850 \mathrm{~nm}$, shown in Figure 1. The results were obtained with two CCD linear cameras: an Action Research 2048-pixel, 12-bit resolution model and a Dalsa Corp. 1024-pixel, 8-bit resolution, high-transfer camera. The former is used when high sensitivity and imaging depth are required, and the latter for fast, real-time imaging (two frames of 400 lines per second) for monitoring conservation treatments.

An interesting example of a process requiring online monitoring is laser ablation to remove varnish. ${ }^{6}$ If varnish is dull or

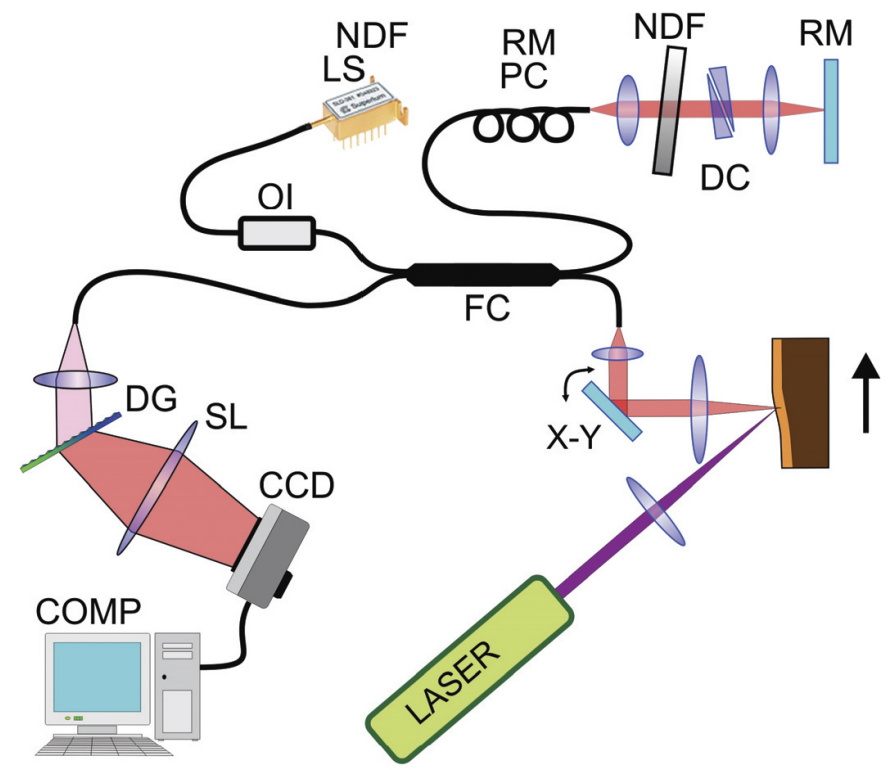

Figure 1. Experimental laser/interferometer artwork-conservation treatment setup. The optical isolator (OI) is inserted between the light source (LS) and the fiber coupler (FC) to protect the former from reflected light. Light passes through the coupler and then propagates in the interferometer's reference and object arms. In the reference arm (top right), it passes through the polarization controller (PC), a neutraldensity filter (NDF), the dispersion compensator (DC), and is then back-reflected by the stationary reference mirror (RM). In the object arm, comprised of transversal scanners $(X-Y)$ and a lens, the light beam is scanned across the object and then backscatters. The returning light from both arms is collected and then analyzed using a spectrometer consisting of the spectrograph lens (SL), diffraction grating (DG), CCD linear camera, and a personal computer (COMP).

yellowed, it must be removed to conserve the art work's paint. Laser ablation is a good alternative when the varnish layer is more resistant than the underlying paint, thus making classic chemical and/or mechanical removal difficult. In contrast to

Continued on next page 
A
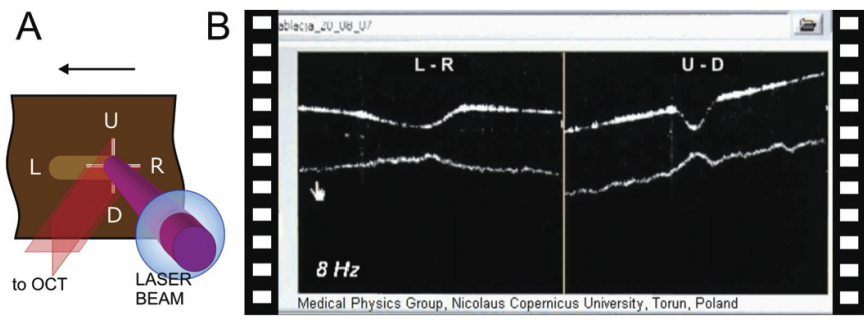

Figure 2. (a) In an experimental configuration, the white cross-left $(L)$, right $(R)$, up $(U)$, and down $(D)$ - shows locations of scanning planes for the OCT movie. (b) Movie frame taken during the ablation experiment. The strong top line on the tomograms is the varnish surface. The line underneath is the varnish/paint-layer interface.

well-established laser cleaning of stones, ${ }^{7}$ in which dark crust ablation from white stone is self-terminated, varnish ablation requires an effective way to monitor the remaining lacquer layer's thickness. We have found that OCT can be used for both realtime monitoring and post-process inspection.

During our ablation experiment, a varnish layer was partially removed from the test sample with an Nd:YAG (neodymiumdoped yttrium aluminum garnet) laser generating $10 \mathrm{~ns}$ UV pulses $(\lambda=266 \mathrm{~nm})$ at frequencies from 2 to $10 \mathrm{~Hz}$. To demonstrate OCT real-time monitoring ability, a video ${ }^{8}$ was taken with an ordinary camera from our OCT system's monitor. The movie (see Figure 2) shows tomograms of cross sections in two directions: left-right (parallel to the groove ablated in the varnish layer) and up-down (perpendicular to the groove). The strong top line on the tomograms is the varnish surface. The line underneath is the varnish/paint-layer interface. The apparent line elevation is caused by refraction: in OCT images, all in-depth distances are optical.

OCT was used for static, high-resolution imaging (see Figure 3) to inspect the ablation process quality. An IR Er:YAG (erbium:YAG) laser $(\lambda=2.936 \mu \mathrm{m})$ was also used. The absorption by the varnish layer was not sufficient to limit heat dissipation to the surface layer, so the interaction of the laser pulse with the paint layer created unwanted exfoliation.

OCT control may make ablation safer for artwork. However, before it is introduced for routine use in conservation, we must confirm that it is safe. We must also consider the long-term photochemical and thermal impact of laser radiation. Nevertheless, a similar approach may be applied to other kinds of laser processing if the treated medium is transparent enough to be visualized with near-IR radiation.

Financial support from the Nicolaus Copernicus University through Rector's Grant 506-F is gratefully acknowledged.

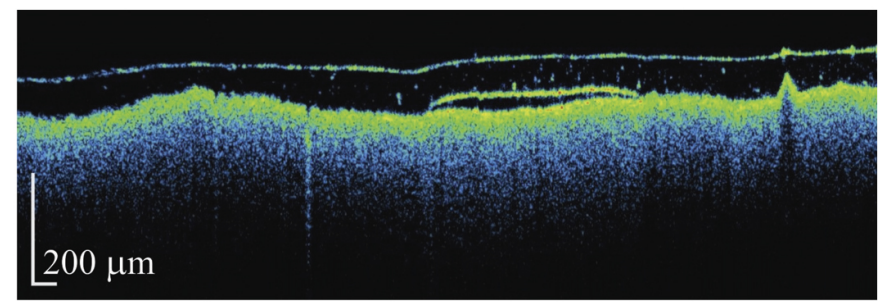

Figure 3. OCT tomogram of an exfoliated varnish layer caused by incorrect ablation conditions.

\section{Author Information}

\section{Piotr Targowski and Michalina Góra}

Institute of Physics

Nicolaus Copernicus University

Torun, Poland

http://www.fizyka.umk.pl/en/phys/institute.html

Piotr Targowski, professor, received his PhD and DrHabil from the Nicolaus Copernicus University. His current research focuses on using spectral-domain OCT to investigate the structure and some properties of museum objects. He is a member of the Polish Photonic and Physical Societies.

Michalina Góra is a PhD student and a Foundation of Polish Science scholar. She is focusing on swept-source OCT for biomedical applications. She is also implementing OCT for structural imaging of artwork.

\section{Jan Marczak and Antoni Rycyk}

Institute of Optoelectronics

Military University of Technology (MUT)

Warsaw, Poland

http://www.wat.edu.pl

Jan Marczak, associate professor, received his $\mathrm{PhD}$ in quantum electronics from MUT. He is a specialist in laser interaction with matter and laser telemetry. He heads MUT's Laboratory of Laser Applications in the Department of Laser Technique.

Antoni Rycyk, MSc, graduated in quantum electronics and solidstate physics from MUT. He is an expert in laser techniques. His main research field is laser interaction with matter. 


\section{Bogumila J. Rouba}

Institute for the Study, Restoration, and Conservation of Cultural Heritage

Nicolaus Copernicus University

Toru, Poland

http:/ / www.konserwacjamalarstwa.umk.pl/

Bogumila J. Rouba is professor and chair of the Painting Conservation Division. Her current research focus is on conservation of mural paintings and oil paintings on canvas, as well as sustainability of the cultural heritage in the face of environmental hazards.

\section{References}

1. D. Huang, E. A. Swanson, C. P. Lin, J. S. Schuman, W. G. Stinson, W. Chang, M. R. Hee, T. Flotte, K. Gregory, C. A. Puliafito, and J. G. Fujimoto, Optical coherence tomography, Science 254, pp. 1178-1181, 1991.

2. http://www.oct4art.eu A complete list of papers on applications of OCT to artwork. Accessed 10 April 2009.

3. H. Liang, S. Martin-Simpson, A. Podoleanu, and D. Saunders, Optical coherence tomography: a non-invasive technique applied to painting conservation, SPIE Newsroom, 2006. http://spie.org/x8875.xml. Accessed 10 April 2009, doi:10.1117/2.1200601.0067

4. D. Stifter, Beyond biomedicine: a review of alternative applications and developments for optical coherence tomography, Appl. Phys. B 88, pp. 337-357, 2007. doi:10.1007/s00340-007-2743-2

5. E. Kwiatkowska, M. Sylwestrzak, B. J. Rouba, L. Tymińska-Widmer, M. Iwanicka, and P. Targowski, Fast optical coherence tomography for non-destructive investigations of structure of easel paintings, Proc. SPIE 7139, p. 713916, 2008 doi:10.1117/12.813477

6. P. Targowski, B. Rouba, M. Góra, L. Tymińska-Widmer, J. Marczak, and A. Kowalczyk, Optical coherence tomography in art diagnostic and restauration, Appl. Phys. A 92, pp. 1-9, 2008. doi:10.1007/s00339-008-4446-x

7. J. Marczak, A. Koss, P. Targowski, M. Góra, M. Strzelec, A. Sarzyński, W. Skrzeczanowski, R. Ostrowski, and A. Rycyk, Characterization of laser cleaning of artworks, Sensors 8, pp. 6507-6548, 2008. doi:10.3390/s8106507

8. Video taken directly from the screen of the OCT tomograph during monitoring of laser ablation of Dammar Matt Varnish.

http://spie.org/documents/newsroom/videos/1589/Fig2.avi 